\title{
EMPREENDEDORISMO NAS UNIVERSIDADES E A RELAÇÃO GOVERNO-EMPRESA- SOCIEDADE-MEIO-AMBIENTE: UM ENSAIO TEÓRICO
}

Vivien Kaniak $^{1}$

Rivanda Meira Teixeira ${ }^{2}$

${ }^{1}$ ciências sociais aplicadas / ESTACIO / FACULDADE ESTACIO DE CURITIBA

${ }^{2}$ Universidade Federal do Paraná - Campus Palotina 


\section{EMPREENDEDORISMO NAS UNIVERSIDADES E A RELAÇAO GOVERNO- EMPRESA-SOCIEDADE-MEIO AMBIENTE: UM ENSAIO TEÓRICO}

Resumo: Estudos sobre universidades empreendedoras revelam um novo papel para a universidade na atualidade que inclui o universo das parcerias colaborativas para promoção de atividades voltadas para o benefício da sociedade, do setor produtivo e do meio-ambiente. Ao discutir esse tema, este ensaio teórico pretende explorar a atuação das universidades empreendedoras em relação à transformação do conhecimento em proveito das entidades como governo, empresas, sociedade e meio ambiente. Por meio de análise sistemática da literatura foram identificadas lacunas que impulsionaram a criação de um framework teórico além de proposições de pesquisa a serem desenvolvidas em estudos futuros. A contribuição prática deste ensaio consiste em subsidiar a formulação de políticas públicas e/ou organizacionais mais efetivas para o empreendedorismo universitário. A contribuição teórica consiste nas proposições apresentadas que podem ser úteis para a realização de estudos futuros sobre o tema que elucidem questões que ainda se encontram em aberto na literatura.

Palavras-chave: Empreendedorismo Universitário. Atividades Empreendedoras na Universidade. Parcerias universitárias. Quíntupla-hélice.

\section{Introdução}

As universidades vêm passando por profundas mudanças com o advento da sociedade do conhecimento, de modo que novas atividades vêm emergindo para atender as demandas atuais (HEATON; LEWIN; TEECE, 2019; LINK; SARALA, 2019). Esse novo modelo de universidade, atento à transformação do conhecimento agregando valor externo ficou conhecido como universidade empreendedora (CLARK, 1998; ETZKOWITZ, 2002).

As pesquisas sobre a natureza das atividades empreendedoras em universidades vem tendo um forte crescimento nas últimas décadas (O’REILLY; ROBBINS, 2018; SIEGEL, D. S.; LEIH, 2018). Uma das razões para esse acontecimento remete para o sucesso da transferência de tecnologia das universidades norte-americanas em meados da década de 80, evento que ficou conhecido como "The Bayh-Dole Act". O ato foi uma ação do congresso do país que introduziu uma nova política de propriedade intelectual e disponibilizou fundos federais para pesquisas, mantendo a posse das invenções para os pesquisadores (DAMSGAARD; THURSBY, 2013; GUERRERO et al., 2016). Já no Brasil merece destaque a criação da lei de inovação n.10.973/2004 (BRASIL, 2004), que foi regulamentada pelo Decreto 5.563, de 2005 e posteriormente revogada pelo Decreto 9.283, de 2018, e trata de medidas de incentivo à inovação e à pesquisa científica e tecnologia. Essa lei deu impulso a criação dos núcleos de inovação tecnológica tanto em universidades e institutos públicos de pesquisa e tecnologia no país que, por sua vez, contribuíram para o aumento do processo de transferência de tecnologia das universidades para empresas, organizações e a comunidade em geral e hoje é considerada um dos pilares do Sistema Nacional de Ciência, Tecnologia e Inovação (MACHADO, P. V.; SARTORI; CRUBELLATE, 2017). 
Em termos de expectativas sociais, tais marcos refletem uma mudança na própria sociedade que demanda que as instituições de ensino assumam responsabilidades mais novas e complexas e que expandam suas missões tradicionais de ensino e pesquisa para que novas atribuições possam se incorporar (FINI, R. et al., 2018; HAYTER, CAHOY, 2016). Dentre essas atribuições Fini et al. (2018) defende que as universidades devem incorporar um papel de responsabilidade social ao desenvolver pesquisas que tragam mudanças ou benefícios para a economia, cultura, políticas públicas, serviços, saúde, meio ambiente ou, ainda, produtos e serviços melhorados com base no conhecimento.

Para que possa cumprir com responsabilidades cada vez mais complexas, as universidades realizam atividades empreendedoras para gerar e transferir o conhecimento e a tecnologia produzida internamente. Essas atividades incluem desde incentivos para geração de propriedade intelectual, criação de novas empresas (spin offs), ensino de empreendedorismo até o oferecimento de consultorias, palestras, atendimentos e demais acordos pontuais realizados com empresas e membros da comunidade (ABREU; GRINEVICH, 2013; GALÁN-MUROS et al., 2017).

Em função desse contexto, este ensaio teórico buscou contribuir teoricamente apresentando considerações sobre a literatura do tema e proposições teóricas que possam embasar futuros estudos que venham a elucidar questões que ainda se encontram em aberto. Além disso, como contribuição prática foi proposto um framework de funcionamento que, se articulado com suas principais entidades parcerias: governo, empresas, sociedade e meioambiente, pode vir a subsidiar na formulação de políticas públicas e/ou organizacionais mais efetivas para o empreendedorismo universitário.

\section{Referencial Teórico}

\subsection{Empreendedorismo Universitário}

A ideia de a ciência atuar como um propulsor do desenvolvimento econômico e social é relativamente antiga, entretanto, somente a partir da década de 1970 é que a universidade passa a desempenhar um papel mais amplo neste cenário (ETZKOWITZ, 2002). Um dos fenômenos que passou a ser considerado um símbolo nesse sentido foi o ocorrido nos EUA, mais especificamente no Vale do Silício, em que as universidades passaram a ter relações de cooperação em pesquisa, intercâmbio e joint ventures de projetos com empresas e universidades do mundo todo (SAXENIAN, 1994). As universidades do Vale do Silício desenvolveram vínculos de cooperação com empresas de tecnologia que passaram a dar suporte desde a formação profissional até o fornecimento de informações para o desenvolvimento de tecnologias, processos e métodos (BUNDERS; BROERSE; ZWEEKHORST, 1999). Seguindo os passos do desenvolvimento empreendedor das universidades a literatura científica também emergiu para analisar o tema (BOZEMAN; FAY; SLADE, 2013).

Etzkowitz foi um dos precursores nesses estudos ainda na década de 90 e vem sendo até hoje um dos mais citados na literatura (MASCARENHAS et al., 2017; SCHMITZ et al., 2017). Inicialmente ele conceituou universidade empreendedora aquela que considera novas fontes de fundos como patentes e pesquisas sob contratos de parceria com empresas privadas (ETZKOWITZ, 1994). Logo após destacou-se o trabalho de Clark (1998) que analisou e identificou algumas características de empreendedorismo universitário que envolviam a busca 
por uma diversificação nas fontes de receita das universidades, além do despertar de uma cultura empreendedora. Em seu estudo sobre universidades empreendedoras europeias, descreve as características de inovação, energia, busca de oportunidades e liderança empreendedora como sendo parte da cultura empreendedora que vinha emergindo na época. Mais tarde-; surgiu a definição de Jacob, Lundqvist e Hellsmark (2003) que propunham a universidade empreendedora como possuinte de uma grande variedade de novos mecanismos de infraestrutura de suporte para impulsionar o empreendedorismo entre organizações, além de o transformar em produto.

Seguindo a mesma linha, Fialho (2007) postula que a universidade empreendedora é aquela que desenvolve competências associadas às posturas empreendedoras a fim de mobilizar recursos internos, conhecimentos, habilidades e atitudes que acabam por promover a inovação. Um ano mais tarde, Guenther e Wagner (2008) esboçam uma definição que privilegia a transferência de tecnologia na qual a universidade deve ser uma organização multifuncional de suporte para a transferência de tecnologia da academia para a indústria e de novos negócios via educação empreendedora.

Em uma análise das definições da última década, nota-se que autores como Abreu e Grinevich, (2013); Guerrero, Urbano, Cunningham e Organ (2014); Hayter e Cahoy, (2016) buscam realçar a importância de a universidade prover um ambiente de suporte no qual a comunidade universitária possa explorar e avaliar ideias que venham a ser transformadas em iniciativas empreendedoras que não privilegiem somente os fatores econômicos mas também sociais. Outros autores como O'Reilly e Robbins (2018) destacam o papel da inovação dentro da universidade e apresentam um estudo no qual universidades que possuem maior cultura de inovação são também as que obtém maior performance em transferência de tecnologia e conseguem, portanto, trazer maiores benefícios aos seus parceiros.

A análise da literatura do tema demonstra que, embora não exista um conceito único de universidade empreendedora, a maioria dos autores denotam uma preocupação com a interação da universidade com o mercado, com a sociedade e as demais instituições que a envolvem. Alguns autores aprofundaram-se mais nos aspectos econômicos (ETZKOWITZ et al., 2000; GUENTHER; WAGNER, 2008; MAZDEH et al., 2013) outros nos aspectos sociais (ABREU; GRINEVICH, 2013; GUERRERO; URBANO, 2012; MAINARDES; ALVES; RAPOSO, 2011; RUDENKO; POGODAEVA; GOLUBEV, 2017) e há ainda os autores que refletiram na questão do meio ambiente (CARAYANNIS; CAMPBELL, 2010; FINI, R. et al., 2018). Mas, de modo geral, todos os autores mencionados percebem as atividades empreendedoras da universidade como um meio de oferecer algum benefício às entidades que a cercam.

\subsection{Atividades Empreendedoras na Universidade}

As atividades das universidades empreendedoras são em geral categorizadas na literatura como formais e informais. As formais são as relacionadas à transferência de tecnologia, a geração de patentes e licenciamentos, atividades de incubação e criação de empresas universitárias e as informais estão ligadas a ações pontualmente realizadas como consultorias, projetos desenvolvidos pelas empresas-júnior, ações externas voltadas para educação empreendedora, oferecimento de palestras e eventos para a comunidade interna e externa (ABREU; GRINEVICH, 2013; ETZKOWITZ, 2004; GUERRERO et al., 2016). 
As atividades de transferência de tecnologia são em geral conduzidas através das denominadas agências de inovação ou núcleos de inovação tecnológica (NITs) no Brasil (MACHADO, H. P. V.; SARTORI; CRUBELLATE, 2017) ou escritórios de transferência de tecnologia (ETTs) conforme denominação em outros países (BENGTSSON, 2017; CLOSS et al., 2012). A transferência de tecnologia pode acontecer de formas diversas. Bekkers e Freitas (2008) citam uma lista de situações nas quais ela ocorre, como: publicações científicas ou relatórios profissionais; contatos informais realizados entre pesquisadores ou representantes de empresas; projetos de pesquisa e desenvolvimento que ocorrem em parceria; financiamentos de projetos stricto-sensu; contratos de pesquisa; uso compartilhado de instalações (laboratórios, equipamentos) e licenciamento de patentes e de know-how. Já Bengtsson (2017) chama atenção para as questões ligadas à gestão da propriedade intelectual, como administração dos contratos de licenciamento e proteção da licença intelectual.

Siegel, Waldman e Link (2003) apontam que a transferência de tecnologia envolve diversas etapas que vão desde a descoberta científica, a revelação da invenção pelos pesquisadores à universidade, a avaliação da invenção para patenteamento, o depósito da patente, a oferta da tecnologia para as empresas ou empreendedores, a negociação da licença e, finalmente, a comercialização formal ou informal da invenção.

$\mathrm{O}$ patenteamento e o licenciamento são importantes atividades que ocorrem na universidade empreendedora, pois colaboram para proteger a propriedade intelectual, além de gerar recursos à universidade em termos de royalties (BOZEMAN; FAY; SLADE, 2013). Ao explorar patentes, torna-se possível para as universidades fazer a venda de licenças às empresas, de modo que o número de licenciamentos está ligado ao número de patentes geradas por uma instituição (FULLER; PICKERNELL, 2018).

As incubadoras universitárias são organizações criadas para hospedar e amparar micro e pequenas empresas com vistas a viabilizar seu desenvolvimento inicial ou até mesmo viabilizar sua criação (STEINER; CASSIM; ROBAZZI, 2013). O objetivo das incubadoras é dar suporte estratégico aos negócios em seus primeiros anos de funcionamento, além de oferecer serviços e consultoria às empresas novatas (PEREIRA; RODRIGUES; RODRIGUES, 2004). Elas se constituem como uma alternativa para alavancar negócios nascentes principalmente viabilizando o nascimento de spin offs que são empresas geralmente fundadas por acadêmicos com o objetivo de explorar tecnologias criadas na universidade-mãe e que podem ter aplicações comerciais capazes de gerar retorno a elas (MIRANDA; CHAMORRO; RUBIO, 2018; O'SHEA et al., 2007).

As consultorias, presentes na maioria das universidades, vem se tornando uma das principais portas de entrada de cooperação, resultando em inúmeros projetos de valor para os envolvidos e na entrada de recursos financeiros para a universidade (CASADO; SILUK; ZAMPIERI, 2012). As consultorias são, em geral, realizadas pelos professores especialistas da instituição de ensino que visam solucionar problemas ou implantar processos de melhoria em empresas públicas ou privadas (MASCARENHAS et al., 2017). As consultorias também acontecem nas empresas-júnior universitárias que são caracterizadas como instituições sem fins lucrativos. Essas empresas são criadas e administradas por alunos dos mais variados cursos com objetivo de possibilitar aos alunos de graduação oportunidades práticas de aprendizado e aquisição de experiência na área, complementando sua formação (CRUZ, 2000). 
Outra atividade que merece atenção entre as universidades empreendedoras é o ensino do empreendedorismo, que visa desenvolver nos alunos as competências que lhes permitam se tornar empreendedores (ABOU-WARDA, 2016). A ideia é que o contato com o empreendedorismo desperte no estudante o interesse e o desejo de empreender além de desenvolver competências importantes, como: senso de auto eficácia, comunicação, habilidades de negociação e persuasão e planejamento de negócios (LIMA et al., 2015; NISTOREANU; GHEORGHE, 2014).

Já a oferta de palestras e eventos voltados para o público externo da universidade é citada por alguns autores como uma das atividades não remuneradas que possui grande potencial para gerar futuras parcerias e empreendimentos (ABREU; GRINEVICH, 2013; GUERRERO; CUNNINGHAM; URBANO, 2015; MEUSBURGER; ANTONITES, 2016). Galán-Muros et al. (2017) sugerem, até mesmo, que os esforços das universidades em redesenhar os currículos trazendo palestrantes da indústria, ainda que requeiram tempo e investimentos, são muitas vezes compensados pelo estabelecimento futuro de parcerias geradoras de recursos, como as consultorias, a venda de patentes e os licenciamentos ou a criação de novas firmas.

Analisando-se a literatura sobre universidades empreendedoras é possível observar que boa parte dos autores se concentra na descrição das atividades empreendedoras que resultam em atrair recursos financeiros para as instituições gerando novas empresas, novos produtos e empregos (MARKUERKIAGA et al., 2016). Entretanto, pouco foi descrito em termos de atividades empreendedoras voltadas para o desenvolvimento social cujo foco fosse a comercialização da ciência como um impulsionador para a mudança social e que trouxesse retornos reais à sociedade (FINI, R. et al., 2018). É nesta lacuna, portanto, que o presente estudo baseia o modelo teórico desenvolvido e as proposições de pesquisa sugeridas.

\section{Metodologia}

O presente ensaio envolveu uma revisão sistemática de literatura que é o método especialmente útil para se administrar um grande número de artigos distribuídos ao longo de um período de tempo e leva em consideração as necessidades de sistematização e reprodutibilidade no desenvolvimento do método (ARMITAGE; KEEBLE-ALLEN, 2008). A técnica também permite que outros pesquisadores possam fazer futuras atualizações da revisão, seguindo o mesmo conjunto de passos estabelecidos (THORPE; HOLT, 2008).

Ao todo oito etapas foram seguidas na busca por estudos relevantes na temática. $\mathrm{Na}$ primeira etapa foram levantadas as revisões de literatura publicadas no tema nas bases de dados da Web of Science, Scopus e EBSCO que ajudaram a ter uma visão geral do tema. Ao todo foram encontradas dez revisões. Desses artigos foram extraídas as palavras-chave para a pesquisa principal. Na segunda etapa foi feita uma nova busca na base de dados a partir das palavras-chave "universit* entrepreneur*" OR "entrepreneur* universit*" OR "academic* entrepreneur*" OR "entrepreneur* academic*" que estivessem contidas no título, resumo ou palavras-chaves sem restrição de data de publicação, mas filtrados por artigos publicados em periódicos e working papers na área de gestão (Management). A busca foi conduzida no mês de dezembro de 2018.

A seguir, todos os títulos e resumos foram analisados e foram excluídos os falsos positivos, isto é, artigos que continham as palavras-chave, porém não eram aderentes a 
temática. Na quarta etapa foram eliminados os artigos que apareciam duplicados nas bases de dados resultando em um total de 393 artigos. Na quinta etapa os resumos foram lidos na íntegra e foram excluídos os artigos que não eram aderentes a proposta deste ensaio, tendo resultado em 242 artigos. Na sexta etapa os artigos foram lidos na íntegra e a seguir tiveram seus conteúdos organizados com auxílio dos fichados com auxílio dos softwares Mendeley ${ }^{\circledR}$ e NVivo®.

O software Mendeley ${ }^{\circledR}$ foi utilizado para organização das referencias bibliográficas e facilitação das citações. O software $\mathrm{NVivo®} \mathrm{foi} \mathrm{a} \mathrm{ferramenta} \mathrm{utilizada} \mathrm{para} \mathrm{auxiliar} \mathrm{no}$ fichamento dos textos, organização dos resumos e análises dos conteúdos.

\section{Proposições sobre a Universidade Empreendedora e Articulação com a Teoria}

Conforme exposto é possível evidenciar que a literatura mais recente dá maior destaque a importância de que o empreendedorismo universitário tenha o foco não somente na angariação de novas fontes de recursos financeiros mas também no atendimento das necessidades da sociedade, de modo a contribuir para o desenvolvimento social de forma mais abrangente (ABREU et al., 2016; FINI, et al., 2018; GUERRERO; CUNNINGHAM; URBANO, 2015; HAYTER; CAHOY, 2016) .

Fini et al. (2018) abordam essa questão e defendem que a universidade deve assumir um papel de responsabilidade social ao desenvolver pesquisas que tragam mudanças ou benefícios para a economia, cultura, políticas públicas, serviços, saúde, meio ambiente ou, ainda, produtos e serviços melhorados com base no conhecimento. Além disso, os autores propõem uma reflexão sobre as preocupações éticas de quem está a beneficiar-se com os impactos da comercialização da ciência e defendem uma mudança no foco. O novo foco proposto seria a comercialização da ciência como um impulsionador da mudança social, que possam abranger a sociedade como um todo. Assim, a comercialização da ciência desempenharia seu papel de facilitador de mudanças sociais, ao invés de apenas buscar resultados monetariamente mensuráveis.

É importante destacar que os autores que defendem este ponto de vista não são desfavoráveis à comercialização da ciência. Tais pesquisadores somente advogam que ela deve atuar como mecanismo para converter investimentos públicos de pesquisa em aplicações práticas com potenciais impactos econômicos e sociais (FINI et al., 2018; GUERRERO et al., 2016; PEREIRA; RODRIGUES; RODRIGUES, 2004).

Seguindo essa lógica, Abreu e Grinevitch (2013) sugerem um modelo de universidade empreendedora que inclui não somente as atividades empreendedoras universitárias normalmente enfocadas que possuem indicadores econômicos objetivos de resultados (como as patentes, spinouts e licenciamentos), mas que contenha também as atividades informais, comerciais e não-comerciais de natureza empreendedora das universidades. Desta forma, as atividades não ficariam restritas ao valor comercial que surge como resultado, mas também ao valor social produzido pelas soluções geradas na universidade.

Agindo desta forma a universidade serviria como canal de ressonância, contribuindo para o desenvolvimento econômico e social por meio de suas múltiplas atividades (GUERRERO; URBANO, 2012). Entretanto autores como Hayter e Cahoy (2016) apresentam uma visão mais crítica em relação ao atual estado da universidade empreendedora. De acordo com eles, as estruturas de gestão estratégica atuais ainda não se adaptaram às 
responsabilidades e impactos sociais necessários para prover uma nova missão no ensino superior. Assim, ainda não dão conta de preencher as demandas atuais da sociedade que incluem novas responsabilidades sociais e operacionalização em contexto mais global de desenvolvimento econômico e sustentabilidade, que permitam, de fato, às universidades maximizarem seu impacto social. ensaio:

Perante as posições expostas apresentam-se as primeiras proposições teóricas deste

P1: As universidades empreendedoras estão dirigindo esforços para se aproximar e responder às demandas socioambientais tanto quanto fazem para abarcar as demandas empresariais?

P2: Quais impactos positivos essas ações estão trazendo para a comunidade local bem como para a sociedade em geral?

Conforme já mencionado, em boa parte das universidades os processos de interação e transferência de tecnologia são conduzidos por meio dos escritórios de transferência de tecnologia (ETTs). A função desses núcleos intermediários é atuar como articuladores das instituições das quais fazem parte, assumindo a comercialização dos resultados obtidos com as produções científicas e a gestão dos recursos recebidos que, muitas vezes, são destinados às pesquisas internas (SCHMITZ et al., 2017). Sinell; Iffländer e Muschner (2017) destacam ainda que tais núcleos estão se tornando indispensáveis para intermediar as questões entre ciência, política, indústria e o público. Assim, a crescente necessidade de realizar parcerias para criar sinergia entre os atores envolvidos no empreendedorismo universitário resultou em alguns modelos que visam explicar essas interações. Desses, os mais citados na literatura são os modelos de tripla, quádrupla e quíntupla hélice.

O modelo da tripla hélice foi desenvolvido por Etzkowitz e Leydesdorff (1996) em janeiro de 1996. Os autores propuseram uma interação comunicativa e dinâmica através de uma aliança entre universidades, empresas e governos que deveriam voltar seus esforços para a inovação e para o desenvolvimento. Tal modelo atingiu influência considerável no campo do empreendedorismo universitário e acabou se tornando um dos mais importantes e discutidos (FOGELBERG; THORPENBERG, 2012). A figura 1 apresenta a ideia conceitual do modelo.

\section{FIGURA 1 - MODELO DA TRIPLA HÉLICE}

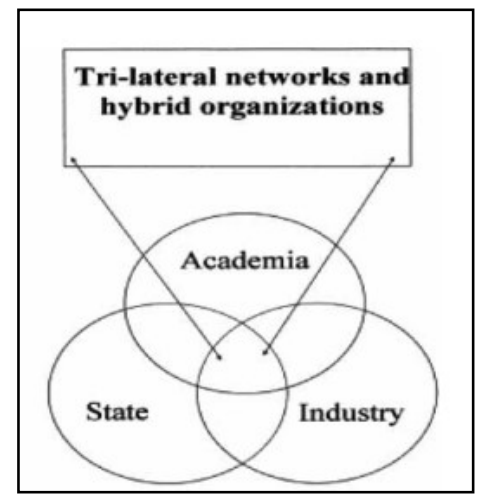

Fonte: Etzkowitz e Leydesdorff (2000) 
Os autores defendem que os três principais atores (universidade-empresa-governo) trabalhem em parceria. A universidade atuaria como indutora das relações com as empresas e o governo como um setor regulador e fomentador da atividade econômica. O produto desta tríade visa a produção de novos conhecimentos, inovação tecnológica e desenvolvimento econômico a ser utilizado nas empresas. Deste modo, as relações entre ciência, tecnologia, pesquisa e desenvolvimento nestas esferas produzem uma dinâmica em espiral, pois suas transações não têm um fim (ETZKOWITZ; LEYDESDORFF, 2000).

Dentro dessa concepção, os grupos de pesquisa universitários atuam como quase-firmas interagindo com as demais hélices, formando, assim, uma universidade empreendedora que viabiliza o funcionamento do modelo (ETZKOWITZ, 2003). Desde a sua criação, o modelo de tripla hélice se difundiu enormemente também no campo de estudos da inovação, sendo sua conceituação uma das mais discutidas e pesquisadas em termos de desenvolvimento da inovação regional (MILLER; MCADAM; MCADAM, 2018).

De acordo com Etzkowitz e Leydesdorff (2000), as três hélices se mantêm em constante interação e se comunicam em diferentes níveis. $\mathrm{O}$ que permite guiar esforços que emergem tanto na criação de spin offs quanto em estratégias de alianças entre empresas, laboratórios governamentais, pesquisa acadêmica e formulação de políticas públicas que impulsionam o desenvolvimento (BARLETTA et al., 2017; FINI et al., 2017; FOGELBERG; THORPENBERG, 2012).

Entretanto, esse modelo não ficou imune a críticas, sendo grande parte delas em relação ao fato de o modelo negligenciar outros atores envolvidos, como empresas de área não tecnológica ou usuários dos produtos (BUNDERS; BROERSE; ZWEEKHORST, 1999; NAKWA; ZAWDIE, 2015). Alguns autores apontam também que o modelo falhou em realizar os níveis esperados de transferência de tecnologia (MCADAM et al., 2012).

Em resposta a essas dificuldades, Carayannis e Campbell (2009) criaram o modelo de quatro hélices com o objetivo de suprir as deficiências apresentadas pelo modelo de três hélices, e que possibilitaria uma variedade maior de inovações. Esse modelo surge em um contexto de globalização, de convergência de sistemas, redes e setores da inovação guiados por grande complexidade e não-linearidade, além dos processos de criação e difusão de conhecimentos muito mais dinâmicos do que haviam sido no passado (CARAYANNIS; CAMPBELL, 2011).

A quarta hélice acrescentada diz respeito à sociedade civil, ou seja, o usuário do produto ou serviço que pode ser representado por uma ampla gama de personagens que vão desde uma firma, uma organização, um único profissional, uma associação de entidade civil ou um cidadão de uma localidade (ARNKIL et al., 2010). Mais tarde, Van Horne e Dutot (2017) defendem que este quarto elemento também pode ser identificado como organizações intermediárias internas à universidade, como um escritório de transferência de tecnologia (ETT) ou uma organização externa à universidade, como um centro de pesquisa governamental ou, ainda, um híbrido entre esses dois, como os parques científicos ou incubadoras, por exemplo. Essa ideia também havia sido sugerida anteriormente por Wright et al., 2008).

Dito de outro modo, a hélice tripla pode ser vista como uma forma de obter inovações de ordem tecnológica, enquanto a hélice quádrupla se refere à obtenção de inovações que são 
demandadas pelos próprios usuários e suas necessidades (CARAYANNIS; CAMPBELL; REHMAN, 2016). A figura 2 apresenta o modelo da quarta hélice.

FIGURA 2 - MODELO DE QUADRUPLA HÉLICE

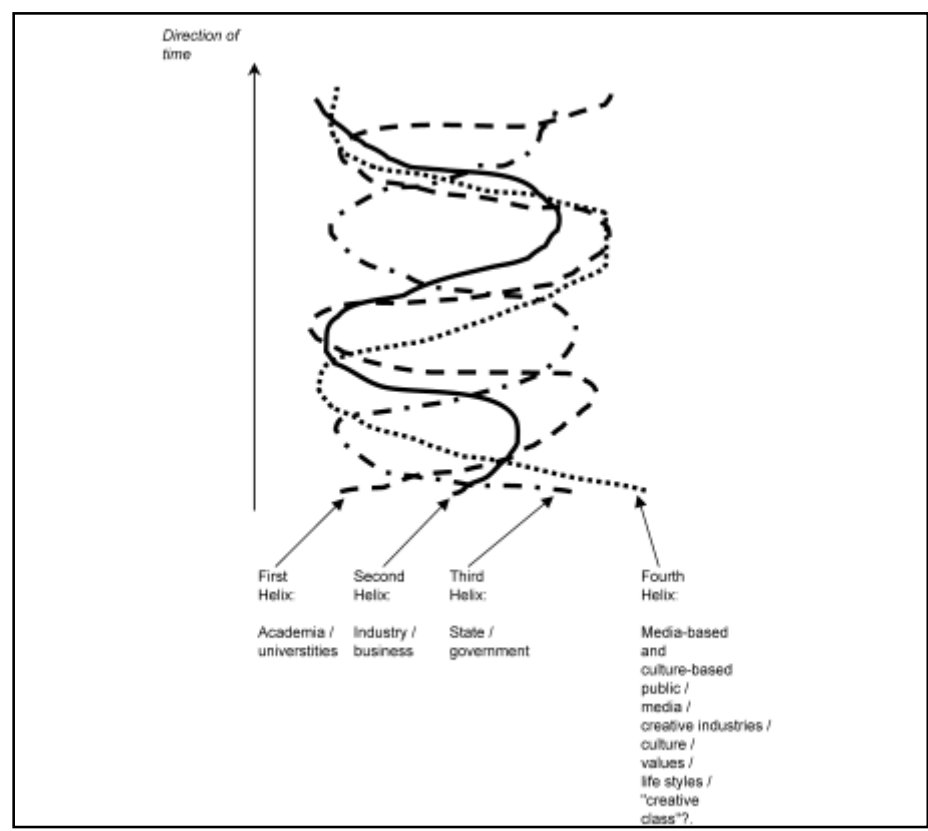

Fonte: Carayannis e Campbell (2009)

Para Miller et al. (2018), a atualidade do modelo da hélice quádrupla reside no fato de a sociedade ser vista como um potencial envolvido na criação dos processos de inovação, um sujeito ativo que cria um efeito impulsionador de inovação. Além disso, eles são os representantes das necessidades da sociedade em termos de transferência de tecnologia de modo a sugerir uma abordagem de inovação aberta onde o conhecimento de vários atores é intercambiado. No entanto, embora este modelo tenha sido muito discutido desde a sua criação, não se pode dizer que ele é um modelo tão reconhecido quanto o da tríplice hélice (MULYANINGSIH, 2015), pois ainda existem poucos estudos sobre ele e ainda menos pesquisas empíricas que deem conta de sua complexidade (VAN HORNE; DUTOT, 2017).

É justamente esse aspecto que traz os desafios para o funcionamento das quatro hélices, como, por exemplo, a diferença entre os interesses dos stakeholders envolvidos. Os professores e pesquisadores universitários, de sua parte, desejam liberdade de tempo e escopo para fazer suas pesquisas, o que não é adequado para a indústria ou até mesmo para as organizações intermediárias que trabalham com prazos fixos ou que possuem interesses de mercado para o desenvolvimento de produtos e serviços. O governo possui sua agenda de interesses que, não raro, é modificada com a troca de mandatos. A sociedade, por sua vez, pode ter uma demanda por rapidez em sua necessidade de solução de problemas. Todos esses aspectos acabam gerando vários pontos a serem alinhados entre os atores (VAN HORNE; DUTOT, 2017).

Em meio às discussões e polêmicas na aplicação do modelo de quatro hélices surge o 
modelo de cinco hélices ou hélices quíntuplas. Este se propõe a ser ainda mais abrangente em sua perspectiva, adicionando a noção de meio ambiente e seu papel no desenvolvimento da inovação. A quinta hélice representa o equilíbrio sustentável entre o desenvolvimento da sociedade, da economia e dos ambientes naturais para que haja progresso como um todo (CARAYANNIS; CAMPBELL, 2010). O conceito de quíntupla hélice engloba o de tripla e quádrupla hélice, pois envolve a ecologia social e o desenvolvimento sustentável da sociedade que irá utilizar os benefícios das inovações produzidas (MULYANINGSIH, 2015). Na figura 3 pode-se visualizar os três modelos, a forma como estão interconectados e a dinâmica de expansão que os caracteriza.

\section{FIGURA 3 - OS MODELOS DE TRIPLA, QUÁDRUPLA E QUÍNTUPLA HÉLICE}

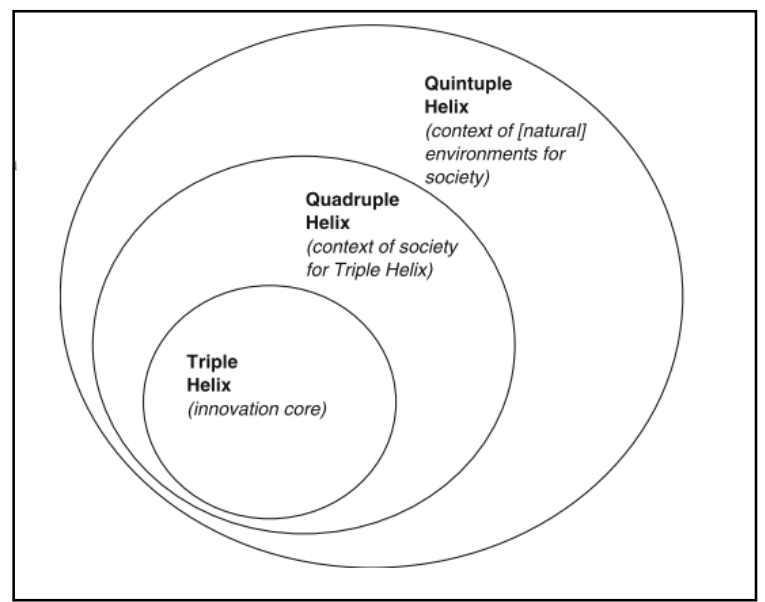

FONTE: Carayannis e Campbell (2011)

Para Carayannis e Campbell (2011), um verdadeiro ecossistema de inovação integra os ambientes sociais naturais e inclui uma diversidade de agentes, atores e organizações que podem ser universidades, pequenas e médias empresas ou grandes corporações que estão envolvidas em redes de inovação heterogêneas ou em clusters de conhecimento.

Dados os principais modelos de interação, coloca-se a terceira e última proposição de pesquisa deste ensaio:

P3: As universidades empreendedoras já estão operando em um modelo de parcerias de cinco hélices que envolve a aliança da universidade com empresas, governo, comunidades/sociedade e preocupação com meio ambiente?

P4: Se as universidades estão operando no modelo de cinco hélices, como são processadas as atividades voltadas ao atendimento das demandas da sociedade e do meio ambiente?

\section{5. $\quad$ Framework de Universidade Empreendedora baseado no Modelo de Cinco Hélices}

A ideia contida no framework aqui proposto foi elaborada com base no modelo de cinco hélices de Carayannis e Campbell (2011) com a proposta de que sejam pesquisadas e descritas com mais profundidade as atividades empreendedoras que vem sendo desenvolvidas atualmente pelas universidades que são voltadas ao modelo da quíntupla hélice, isto é, relativas às parcerias que envolvem universidade-empresas-governo-sociedade-meio- 
ambiente. Conforme análise da literatura apresentada, essas são as atividades que receberam menos atenção na literatura, de modo que, pouco de sua forma de operacionalização e funcionamento são conhecidos.

A proposta deste framework também segue a concepção dos autores originais da quíntupla hélice de que a universidade empreendedora receba de igual maneira e atenda as demandas de todos seus parceiros e colocada em colaboração com governos, empresas, sociedade e meio ambiente agindo para maximizar ações no sentido de manter uma relação de longo prazo. Desta forma, os benefícios gerados seriam tanto econômicos quanto sociais e ambientais, comtemplando a todos os parceiros de maneira equilibrada. Assim a proposta é elucidar quais são as atividades desenvolvidas pelas universidades que contemplam o modelo de cinco hélices e como essas atividades são processadas e operacionalizadas na prática. A figura 1 ilustra o framework proposto:

\section{FIGURA 1 -FRAMEWORK DE UNIVERSIDADE EMPREENDEDORA BASEADO NO MODELO DE CINCO HÉLICES}

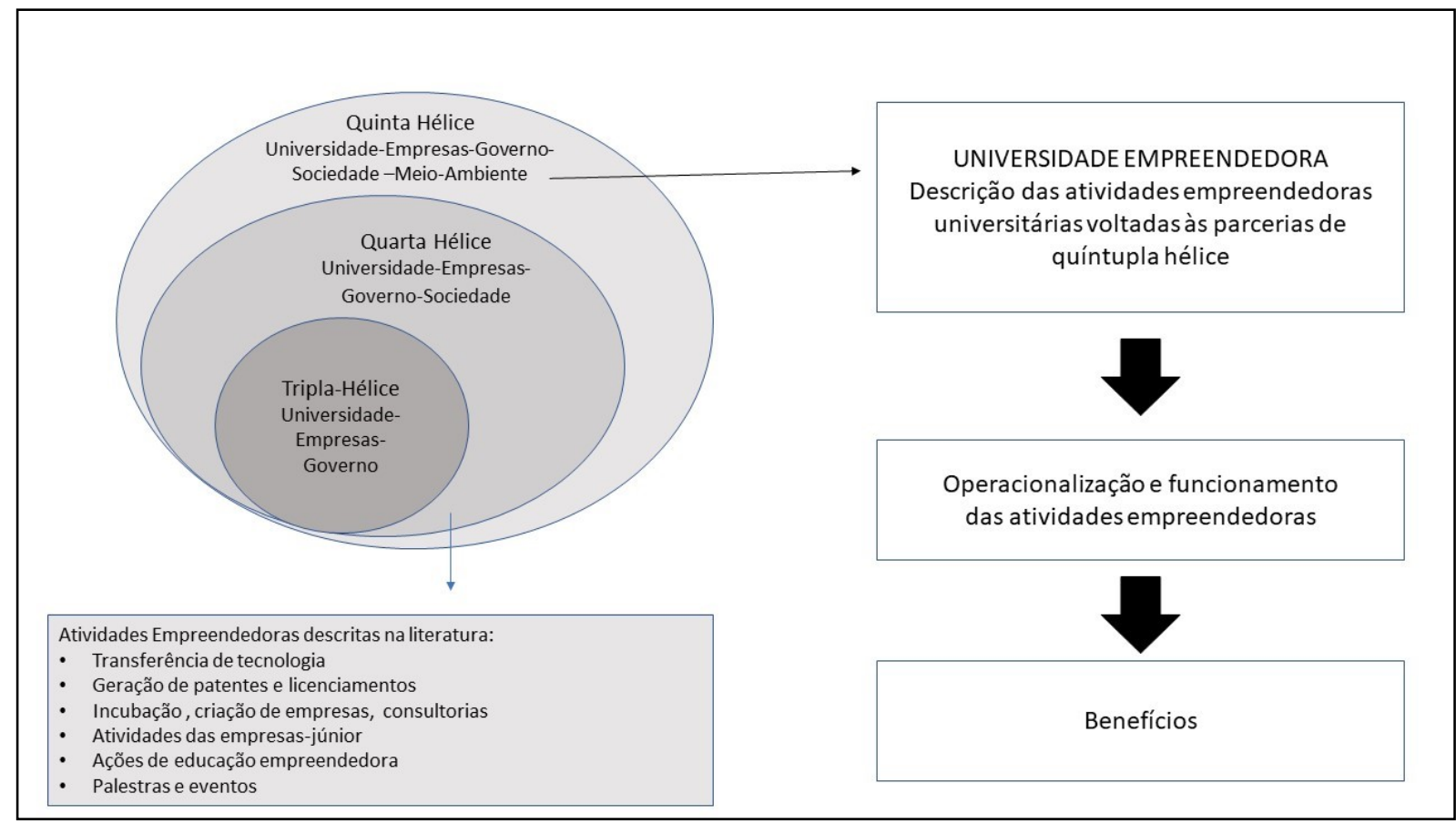

Fonte: Elaborado pelas autoras (2019) com base em Carayannis e Campbell (2011)

O framework retrata cada um dos modelos de interação da universidade empreendedora: o modelo de tripla-hélice, de quarta hélice e de quinta hélice e sua interconexão conforme proposto por Carayannis e Campbell (2011). Também são apresentadas as atividades empreendedoras descritas na literatura que, no geral, referem-se às atividades da tripla e quarta hélice como: transferência de tecnologia, geração de patentes e licenciamentos, incubação, criação de empresas, consultorias, atividades das empresas-júnior, ações de educação empreendedora, palestras e eventos (ABREU; GRINEVICH, 2013; ETZKOWITZ, 2004; GUERRERO et al., 2016). A seguir propõe-se que sejam pesquisadas as atividades 
empreendedoras universitárias que sejam voltadas à proposta da quíntupla hélice bem como qual suas formas de operacionalização e funcionamento por parte da universidade. Além disso sugere-se a elucidação dos benefícios criados para as entidades envolvidas.

A concepção do framework orienta-se sob a ideia de que a universidade emerge na atualidade como arquiteta de uma prosperidade voltada a todos os atores envolvidos e fundada em uma base sólida de conhecimento e experiência científica e tecnológica. Entretanto, para que isso aconteça é necessário que a universidade desempenhe atividades voltadas a satisfação das demandas e integração de interesses de todos os parceiros envolvidos. Para tanto é igualmente importante que se desvende quais são os processos e métodos de funcionamento de cada atividade empreendedora e uma vez que, no modelo proposto, as demandas de entidades como a sociedade e o meio ambiente devem ser igualmente levadas em consideração.

\section{Considerações Finais}

Um crescente conjunto de pesquisas sobre universidade e suas atividades empreendedoras destaca a importância da consolidação de um novo papel da universidade perante entidades parcerias como governos, empresas, sociedade e meio ambiente. Partindo desta emergente literatura este ensaio discutiu o papel da universidade empreendedora e a sua importância da transformação do conhecimento em benefícios igualitários para as várias entidades que a cercam. Lacunas na literatura envolvendo as atividades empreendedoras universitárias foram apontadas e a partir delas foram desenvolvidas proposições teóricas com a finalidade de motivar estudos futuros que possam melhor explorar questões em aberto como: Quais atividades da universidade empreendedora vem sendo direcionadas para o atendimento das demandas socioambientais? De que maneira estão sendo operacionalizas essas atividades? Quais os benefícios gerados por elas?

Baseado nessas proposições e na literatura um framework retratando os modelos de interação das universidades empreendedoras foi construído a fim de gerar reflexões sobre o tema. Esse ensaio adiciona valor a literatura de empreendedorismo universitário ao oferecer aos pesquisadores futuras possibilidades de pesquisa por meio do framework e da plataforma de proposições apresentada. Além disso esse ensaio visou contribuir para repensar o papel da universidade na atualidade, o que pode vir a facilitar a formulação de políticas públicas e organizacionais mais assertivas.

As limitações deste trabalho referem-se à aspectos do framework apresentado como os relativos à mensuração dos benefícios gerados, já que pode tratar-se de resultados menos palpáveis e a serem percebidos no longo prazo. Além disso, trata-se de um framework teórico que necessita ser testado empiricamente no futuro a fim de garantir sua validade e aplicabilidade.

\section{REFERÊNCIAS}

ABREU, M. et al. Entrepreneurial practices in research-intensive and teaching-led universities. Small Business Economics, v. 47, n. 3, p. 695-717, 2016.

ABREU, M.; GRINEVICH, V. The nature of academic entrepreneurship in the UK:

Widening the focus on entrepreneurial activities. Research Policy, v. 42, n. 2, p. 408-422, 1 mar. 2013. 
ARMITAGE, A.; KEEBLE-ALLEN, D. Undertaking a structured literature review or structuring a literature review: Tales from the field. Electronic Journal of Business Research Methods, v. 6, n. 2, p. 103-114, 2008.

ARNKIL, R. A. et al. Exploring quadruple helix outlining user-oriented innovation models. 2010.

BARLETTA, F. et al. Exploring scientific productivity and transfer activities: Evidence from Argentinean ICT research groups. Research Policy, v. 46, n. 8, p. 1361-1369, 2017.

BOZEMAN, B.; FAY, D.; SLADE, C. P. Research collaboration in universities and academic entrepreneurship: the-state-of-the-art. The Journal of Technology Transfer, v. 38, n. 1, p. 167, 28 fev. 2013..

BRASIL. Lei n. 10.973, de 2 de dezembro de 2004. Brasília - DF, 2004.

BUNDERS, J.; BROERSE, J.; ZWEEKHORST, M. B. M. The triple helix enriched with the user perspective: A view from Bangladesh. The Journal of Technology, v. 24, n. 2/3, p. 235246, 1999.

CARAYANNIS, E. G.; CAMPBELL, D. F. Mode 3 and quadruple helix: Toward a 21st century fractal innovation ecosystem. International Journal of Technology Management and Sustainable Development, v. 46, p. 201-234, 2009.

CARAYANNIS, E. G.; CAMPBELL, D. F. J. Open Innovation Diplomacy and a 21st Century Fractal Research, Education and Innovation (FREIE) Ecosystem: Building on the Quadruple and Quintuple Helix Innovation Concepts and the "Mode 3" Knowledge Production System. Journal of the Knowledge Economy, v. 2, n. 3, p. 327-372, 2011. CARAYANNIS, E. G.; CAMPBELL, D. F. J. Triple Helix, Quadruple Helix and Quintuple Helix and how do knowledge, innovation and the environment relate to each other? A proposed framework for a trans-disciplinary analysis of sustainable development and social ecology. International Journal of Social Ecology and Sustainable Development, v. 1, n. 1, p. 41-69, 2010.

CARAYANNIS, E. G.; CAMPBELL, D. F.; REHMAN, S. S. Mode 3 Knowledge Production in Quadruple and Entrepreneurship for Development. Journal of Innovation and Entrepreneurship (2016), v. 5, n. 17, p. 1-24, 2016.

CLARK, B. Creating Entrepreneurial Universities. Organisational Pathways of Transformation. Oxford: Pergamon and Elsevier Science, 1998.

CRUZ, C. H. DE B. A Universidade, a empresa e a pesquisa que o país precisa. Parcerias Estratégicas. Centro de Estudos Estratégicos do Ministério da Ciência e Tecnologia, 2000. v. 8. p. 5-30.

DAMSGAARD, E. F.; THURSBY, M. C. University Entrepreneurship and Professor Privilege University. Industrial and Corporate Change, v. 22, n. 1, p. 183-218, 1 fev. 2013. ETZKOWITZ, H. MIT and the Rise of Entrepreneurial Science. New York: Guedes, 2002. ETZKOWITZ, H. Research groups as quasi-firms: the invention of the entrepreneurial university. Research Policy, v. 32, n. 1, p. 109-121, 2003.

ETZKOWITZ, H. The evolution of the entrepreneurial university. Int. J. Technology and Globalisation, v. 1, n. 1, p. 64-77, 2004.

ETZKOWITZ, H. et al. The future of the university and the university of the future: evolution of ivory tower to entrepreneurial paradigm. Research Policy, v. 29, n. 2, p. 313-330, 2000. 
ETZKOWITZ, H.; LEYDESDORFF, L. The dynamics of innovation: from National Systems and "Mode 2" to a Triple Helix of university-industry-government relations. Reserarch Policy, v. 29, n. 2, p. 109-123, 2000.

FIALHO, F. A. P. Empreendedorismo na era do conhecimento. Florianópolis: Visual Books, 2007.

FINI, R. et al. Re-thinking the commercialization of public science: from entrepreneurial outcomes to societal impacts. Academy of management Perspectives, v. 6, n. 6, p. 1-25, 2018. FOGELBERG, H.; THORPENBERG, S. Regional innovation policy and public - private partnership : The case of Triple Helix Arenas in Western Sweden. Science and Public Policy, v. 39, p. 347-356, 2012.

GALÁN-MUROS, V. et al. Nurture over nature: How do European universities support their collaboration with business? Journal of Technology Transfer, v. 42, n. 1, p. 184-205, 22 fev. 2017.

GRIMALDI, R. et al. 30 years after Bayh-Dole: Reassessing academic entrepreneurship. Research Policy, v. 40, n. 8, p. 1045-1057, 1 out. 2011.

GUENTHER, J.; WAGNER, K. Getting out of the ivory tower - new perspectives on the entrepreneurial university. European Journal of International Management, v. 2, n. 400-417, 2008.

GUERRERO, M. et al. Entrepreneurial universities: emerging models in the new social and economic landscape. Small Business Economics, v. 47, n. 3, p. 551-563, 14 out. 2016. GUERRERO, M. et al. Entrepreneurial universities in two European regions: a case study comparison. The Journal of Technology Transfer, v. 39, n. 3, p. 415-434, 6 jun. 2014. GUERRERO, M.; CUNNINGHAM, J. A.; URBANO, D. Economic impact of entrepreneurial universities' activities: an exploratory study of the United Kingdom. Research Policy, v. 44, n. 3, p. 748-764, 1 abr. 2015.

GUERRERO, M.; URBANO, D. The development of an entrepreneurial university. The Journal of Technology Transfer, v. 37, n. 1, p. 43-74, 27 fev. 2012.

HAYTER, C. S.; CAHOY, D. R. Toward a strategic view of higher education social responsibilities: A dynamic capabilities approach. Strategic Organization, v. 16, n. 1, p. $12-$ 34, 2016.

HEATON, S.; LEWIN, D.; TEECE, D. Managing campus entrepreneurship: Dynamic capabilities and university leadership. Managerial and Decision Economics, n. January, p. 1$15,2019$.

JACOB, M.; LUNDQVIST, M.; HELLSMARK, H. Entrepreneurial transformations in the Swedish university system: the case of Chalmers University of Technology. Research Policy, v. 32, n. 9, p. 1555-1568, 2003.

LEYDESDORFF, L.; ETZKOWITZ, H. Emergence of a Triple Helix of university-industrygovernment relations. Science and Public Policy., v. 23, n. 5, p. 279-286, 1996.

LIMA, E. et al. Opportunities to Improve Entrepreneurship Education: Contributions Considering Brazilian Challenges. Journal of Small Business Management, v. 53, n. 4, p. 1033-1051, 1 out. 2015.

LINK, A. N.; SARALA, R. M. Advancing conceptualisation of university entrepreneurial ecosystems: The role of knowledge-intensive entrepreneurial firms. International Small Business Journal, v. 37, n. 3, p. 289-310, 2019. 
MACHADO, H. P. V.; SARTORI, R.; CRUBELLATE, J. M. Institucionalização De Núcleos De Inovação Tecnológica Em Instituições De Ciência E Tecnologia Da Região Sul Do Brasil. REAd. Revista Eletrônica de Administração (Porto Alegre), v. 23, n. 3, p. 5-31, 2017. MACHADO, P. V.; SARTORI, R.; CRUBELLATE, J. M. Institucionalização de núcleos de inovação tecnológica em instituições de ciência e tecnologia da região sul do Brasil. REAd. Revista Eletrônica de Administração (Porto Alegre), v. 23, n. 3, p. 5-31, 2017.

MAINARDES, E. W.; ALVES, H.; RAPOSO, M. The process of change in university management: from the Bivory tower to entrepreneurialism. Transylvanian Review ofAdministrative Sciences, v. 33, p. 124-149, 2011.

MALDONADO, V.; LOBERA, J.; ESCRIGAS, C. The role of higher education in a new quadruple helix context. Proceedings of the Triple Helix June 17-19, 2009, Glasgow, UK. 2009, Glasgow, UK, 2009. p. 17-19.

MARKUERKIAGA, L. et al. Factors fostering students' spin-off firm formation: An empirical comparative study of universities from North and South Europe \&quot;Factors fostering students' spin-off firm formation: An empirical comparative study of universities from North and South . Journal of Management Development, v. 35, n. 6, p. 814-846, 2016. MASCARENHAS, C. et al. Entrepreneurial university: towards a better understanding of past trends and future directions. Journal of Enterprising Communities: People and Places in the Global Economy, v. 11, n. 3, p. 316-338, 10 jul. 2017.

MAZDEH, M. M. et al. An empirical investigation of entrepreneurship intensity in Iranian state universities. Higher Education, v. 65, n. 2, p. 207-226, 2013.

MCADAM, R. et al. The development of university technology trans- fer stakeholder relationships at a regional level: lessons for the future. Technovation, v. 32, p. 57-67, 2012. MILLER, K.; MCADAM, R.; MCADAM, M. A systematic literature review of university technology transfer from a quadruple helix perspective: toward a research agenda. $R \& D$ Management, v. 48, n. 1, p. 7-24, 2018.

MULYANINGSIH, H. D. D. Enhancing innovation in quadruple helix perspective: The case of the business incubators in Indonesia. International Business Management, v. 9, n. 4, p. 367-371, 2015.

NAKWA, K., ZAWDIE, G. Structural holes, knowledge intermediaries and evolution of the triple helix system with reference to the hard disk drive industry in Thailand. International Journal of Technology Management and Sustainable Development, v. 14, n. 1, p. 29-48, 2015.

NISTOREANU, B. G.; GHEORGHE, G. The perception of the academics and students regarding the entrepreneurial education in economic education. Amfiteatru Economic, v. 16, n. 37, p. 811-826, 2014.

O'REILLY, N. M.; ROBBINS, P. Dynamic capabilities and the entrepreneurial university: a perspective on the knowledge transfer capabilities of universities. Journal of Small Business and Entrepreneurship, v. 0, n. 0, p. 1-21, 2018.

RUDENKO, D.; POGODAEVA, T.; GOLUBEV, E. Transition towards an entrepreneurial university: a case study of the Tyumen State University. International Journal of Business and Globalisation, v. 18, n. 1, p. 96, 2017.

SAXENIAN, A. Regional advantage. Boston: Harvard Business School Press, 1994.

SCHMITZ, A. et al. Innovation and entrepreneurship in the academic setting: a systematic 
literature review. International Entrepreneurship and Management Journal, v. 13, n. 2, p. 369-395, 2017.

SIEGEL, D. S.; LEIH, S. Strategic management theory and universities : An overview of the Special Issue. Strategic Organization, v. 16, n. 1, p. 6-11, 2018.

SIEGEL, DONALD S.; WRIGHT, M. Academic Entrepreneurship: Time for a Rethink? British Journal of Management, v. 26, n. 4, p. 582-595, 2015.

SINELL, A.; IFFLÄNDER, V.; MUSCHNER, A. Uncovering transfer - a cross-national comparative analysis. European Journal of Innovation Management, v. 21, n. 1, p. 70-95, 2017.

THORPE, R.; HOLT, R. The Sage dictionary of qualitative management research. [S.1.]: Sage Publications, 2008.

ULVENBLAD, P.; BERGGREN, E.; WINBORG, J. The role of entrepreneurship education and start-up experience for handling communication and liability of newness. International Journal of Entrepreneurial Behavior \& Research, v. 19, n. 2, p. 187-209, 10 mar. 2013.

VAN HORNE, C.; DUTOT, V. Challenges in technology transfer: an actor perspective in a quadruple helix environment. Journal of Technology Transfer, v. 42, n. 2, p. 285-301, 2017. WRIGHT, M. et al. Mid-range universities' linkages with industry: Knowledge types and the roles of intermediaries. Research Policy, v. 37, p. 1205-1223, 2008. 